\title{
Isolation of oxidase-positive Gram-negative cocci not belonging to the genus Neisseria from the urogenital tract
}

\author{
D. J. PLATT AND J. J. S. SNELL
}

\begin{abstract}
From the Department of Medical Microbiology, Charing Cross Hospital, Fulham Palace Road, London W6 8RF and the National Collection of Type Cultures, Central Public Health Laboratory, Colindale NW9 5HT
\end{abstract}

SYNOPSIS In a 12-month period, oxidase-positive, Gram-negative cocci showing similar characteristics in biochemical tests have been isolated from the urogenital tract of 39 male and female patients. Although these organisms superficially resemble Neisseria gonorrhoeae, biochemical characterization and the results of DNA base composition analysis indicate that they do not belong to the genus Neisseria. The relationship of these organisms to the genera Neisseria, Achromobacter, and Pseudomonas is discussed.

The isolation of Neisseria spp other than Neisseria gonorrhoeae from the urogenital tract has been reported (Wilkinson, 1952). More recently, Jephcott and Morton (1972) have reported the isolation of $N$. lactamicus from a genital site, and $N$. meningitidis has been similarly found in both symptomatic (Beck et al, 1974) and asymptomatic patients (Volk and Kraus, 1973).

The isolation of these organisms from a small but significant proportion of the patients attending special clinics can lead to difficulty in the diagnosis of gonorrhoea.

Further complications may arise from the observation, in direct smears, of organisms morphologically resembling gonococci, which on culture prove to be coccoid forms of Gram-negative bacilli.

This communication records the isolation of oxidase-positive, Gram-negative cocci, showing similar characteristics in biochemical tests, from the urogenital tract of 39 patients attending the Department of Genitourinary Medicine at this hospital over a period of 12 months. These organisms grew profusely on nutrient agar and formed mucoid colonies which developed a pink pigment. Further study showed that these organisms differ in other fundamental characteristics from members of the genus Neisseria.

\section{Material and Methods}

COLLECTION OF CLINICAL MATERIAL Swabs of material from the urethra, cervix, and Received for publication 28 October 1975 rectum were inoculated on to a modified Thayer Martin medium (Riddell and Buck, 1970) and incubated in candle extinction jars at $37^{\circ} \mathrm{C}$ for 48 hours.

\section{BACTERIOLOGICAL PROCEDURES}

Oxidase-positive colonies were examined in thin films by Gram stain and also with a fluorescein conjugated antigonococcal globulin (Difco) routinely used in this department for the confirmation of the identity of $N$. gonorrhoeae as previously described by Beck et al (1974). The ability to produce acid from glucose, maltose, sucrose, fructose, and lactose was examined using serum agar sugars. Antibiotic sensitivities were determined by the disc technique using Direct Sensitivity Agar (Oxoid) containing $5 \%$ lysed horse blood.

Biochemical tests were performed using the methods and media described by Cowan and Steel (1965), Snell et al (1972), and Owen and Snell (1973).

Pigment was extracted from a 72-hour culture on nutrient agar using a mixture of diethyl ether: methanol $(9: 1)$. The absorption maxima of the extract were measured using a Unicam SP800 recording spectrophotometer.

Inclusions of ferrous or ferric iron were sought using the Tirmann-Schmelzer's Turnbull, and Perl reactions respectively (Culling, 1974).

DEOXYRIBONUCLEIC ACID BASE

COMPOSITION

DNA was extracted by the method of Marmur (1961), and base compositions were estimated by the 
melting temperature (Tm) method of Marmur and Doty (1962). Tm determinations were made in $0 \cdot 1$ standard saline citrate buffer. The equation relating $\mathrm{Tm}$ to the percentage of guanine and cytosine in the total DNA ( $\%$ GC) was derived from the general equation of Owen et al (1969) which for 0.1 SSC reduces to: $\mathrm{GC}=2.087(\mathrm{Tm}-175 \cdot 95)+260 \cdot 34$.

\section{ELECTRON MICROSCOPY}

Twenty-four and 48-hour cultures were examined by negative staining (with $2 \%$ phosphotungstic acid at pH 6.8) and in section (following glutaraldehyde fixation, post-fixation with osmium tetroxide, and staining with uranyl acetate/lead citrate) using a Phillips EM200.

\section{Results}

DISTRIBUTION OF ISOLATES

Table I shows the distribution among the 39 patients, by sex and site, of the isolates.

\begin{tabular}{llll}
\hline Site of Isolation & $\begin{array}{c}\text { Male } \\
n=19\end{array}$ & $\begin{array}{l}\text { Female } \\
n=20\end{array}$ & $\begin{array}{l}\text { Total } \\
n=39\end{array}$ \\
\hline Urethra & 14 & 10 & 24 \\
Cervix only & - & 5 & 5 \\
Urethra and cervix & - & 5 & 5 \\
Rectum & 5 & - & 5 \\
Total & 19 & 20 & 39 \\
\hline
\end{tabular}

Table I Distribution of isolates

Presenting symptoms among the 39 patients were: 응 5 patients with symptoms attributable to tricho- $\overrightarrow{\vec{F}}$ moniasis or candidiasis (confirmed by culture); 10 patients from whom no established pathogen was isolated (clinically non-specific genital infection); 24 asymptomatic patients (attending either as sexual $\vec{\sigma}$ contacts of patients with established clinical condi- $\varnothing$ tions or for routine/post-treatment check-ups). $N$. ॐ gonorrhoeae had been isolated from nine of these $\vec{\circ}$ 24 patients less than one month before detection of this organism.

This organism was recovered on two occasions from five of the 39 patients, and on three separate $\frac{8}{0}$ occasions from one of the patients, the longest period observed between isolations being $7 \frac{1}{2}$ months. $\dot{0}$ Isolations were obtained from 10 of the 39 patients after their first visit to this clinic. Direct microscopy showed the presence of extracellular Gram-negative diplococci on two occasions.

\section{CHARACTERISTICS OF ORGANISMS}

The results of the characterization tests on 10 of the $\vec{\theta}$ strains studied in detail are shown in table II. Gram oे stained preparation of cultures showed the cells to 0 be Gram-negative cocci. The average diameter of the cells was $1 \mu$, although larger forms (up to $3 \mu$ ) were often present. The cells were arranged singly, in pairs, and occasionally in clusters of up to ten.

After overnight incubation at $37^{\circ} \mathrm{C}$ on nutrient

Tests Positive

Growth nutrient agar

Growth at $22^{\circ} \mathrm{C}$

Growth at $30^{\circ} \mathrm{C}$

Growth at $37^{\circ} \mathrm{C}$

Catalase production

Oxidase production

Growth on MacConkey's agar $( \pm)^{1}$

Anaerobic growth (blood agar) $( \pm)$

Tests Negative

Citrate utilization (Koser's)

Indole production

Methyl red test

Acetylmethyl carbinol production

Nitrite reduction

Gelatin liquefaction

Serum liquefaction

$\mathrm{O} / \mathrm{F}$ test (alkaline reaction)

Acid production from ${ }^{2}$ glucose, lactose, sucrose, maltose

Gluconate oxidation

Malonate utilization

Arginine desimidase

Urease production
Phenylalanine deamination ${ }^{2}$
Poly-beta-hydroxybutyrate
inclusion granules
Growth on $2 \%$ sodium chloride
Growth on $4 \%$ sodium chloride

\author{
Ornithine decarboxylase \\ Lysine decarboxylase \\ Growth at $5^{\circ} \mathrm{C}$ \\ Lecithinase production \\ Aesculin hydrolysis \\ Starch hydrolysis \\ Casein hydrolysis \\ Phosphatase production \\ Deoxyribonuclease production \\ Tween 80 hydrolysis \\ Growth on $6 \%$ sodium chloride \\ Nitrate reduction
}

Tests Variable

Hydrogen sulphide production

Growth at $45^{\circ} \mathrm{C}$

Tween 20 hydrolysis

Citrate utilization (Christensen's)

Tween 40 hydrolysis

$1( \pm)$ strain positive

$1( \pm$ ) strain positive

7 strains positive

$3( \pm)$ strains positive strain positive

Table II Biochemical characters of 10 strains

${ }^{1}( \pm)$ indicates poor growth or a weak positive reaction.

'Phenylalanine deamination: method of Snell and Davey (1971).

'Carbohydrates tested in serum agar sugars, peptone water sugars, and ammonium salt sugars. Glucose also tested in Hugh and Leifson's medium and lactose in $10 \%$ lactose agar. 
agar the strains formed convex, translucent, greyish mucoid colonies, $\mathbf{0} \cdot 5-2 \mathrm{~mm}$ in diameter. The colonies developed a pale coral pink pigmentation which was scarcely noticeable after 24 hours' incubation but which increased in intensity after exposure to light for several days. No haemolysis was observed on $5 \%$ horse blood agar. All isolates were capsulated. Motility was not demonstrated.

The isolates gave variable and poorly reproducible results on staining with fluorescein-labelled antigonococcal globulin. Eleven of the 45 strains exhibited an intensity of fluorescence at isolation as bright as $N$. gonorrhoeae. Sixteen isolates were examined in triplicate by this technique. Twelve gave strong fluorescence on at least one occasion, but no isolate gave strong fluorescence on three occasions. These results suggest non-specific fluorescence although we are unable to explain the degree of variability observed. Triplicate controls of $N$. gonorrhoeae and N. perflava showed strong and zero fluorescence respectively on each occasion.

Of 12 isolates, all were sensitive to streptomycin (25 $\mu \mathrm{g} / \mathrm{disc})$, kanamycin (30 $\mu \mathrm{g} / \mathrm{disc})$, gentamicin $(5 \mu \mathrm{g} / \mathrm{disc})$, and tetracycline $(10 \mu \mathrm{g} / \mathrm{disc})$; all were resistant to sulphonamide ( $500 \mu \mathrm{g} / \mathrm{disc})$, co-trimoxazole $(25 \mu \mathrm{g} / \mathrm{disc})$, penicillin $(1.5 \mu \mathrm{g} / \mathrm{disc})$, ampicillin $(2 \mu \mathrm{g} /$ disc), cephaloridine $(25 \mu \mathrm{g} /$ disc), colistin (10 $\mu \mathrm{g} / \mathrm{disc}$ ), and nitrofurantoin (200 $\mu \mathrm{g} /$ disc). Nine strains were sensitive and three resistant to nalidixic acid (30 $\mu \mathrm{g} / \mathrm{disc})$.

\section{DNA BASE COMPOSITIONS}

The Tms of the two strains examined were $83.9^{\circ} \mathrm{C}$ and $84 \cdot 1{ }^{\circ} \mathrm{C}$. These correspond to 68.2 and $68.7 \%$ GC.

\section{ELECTRON MICROSCOPY}

Electron microscopy confirmed the coccoid shape of the cells (fig 1). Figure 2 shows a group of several cells enclosed in what appears to be a common capsule. Figure 3 suggests the presence of a triple layered cell wall structure which agrees with the Gram-negative staining reaction of the cells.

PIGMENT CHARACTERIZATION

Extracts of the pigments showed absorption maxima at 465,490 , and $525 \mathrm{~nm}$. This suggests a carotenoid type of pigment (Pfennig, 1969).

STAIN FOR IRON INCLUSION GRANULES

Iron inclusion granules were not conclusively demonstrated. In no case was a stronger reaction obtained than with an Escherichia coli negative control.
Fig 1 Coccal shape of the cells demonstrated by negative staining ( $\times$ 4600). 


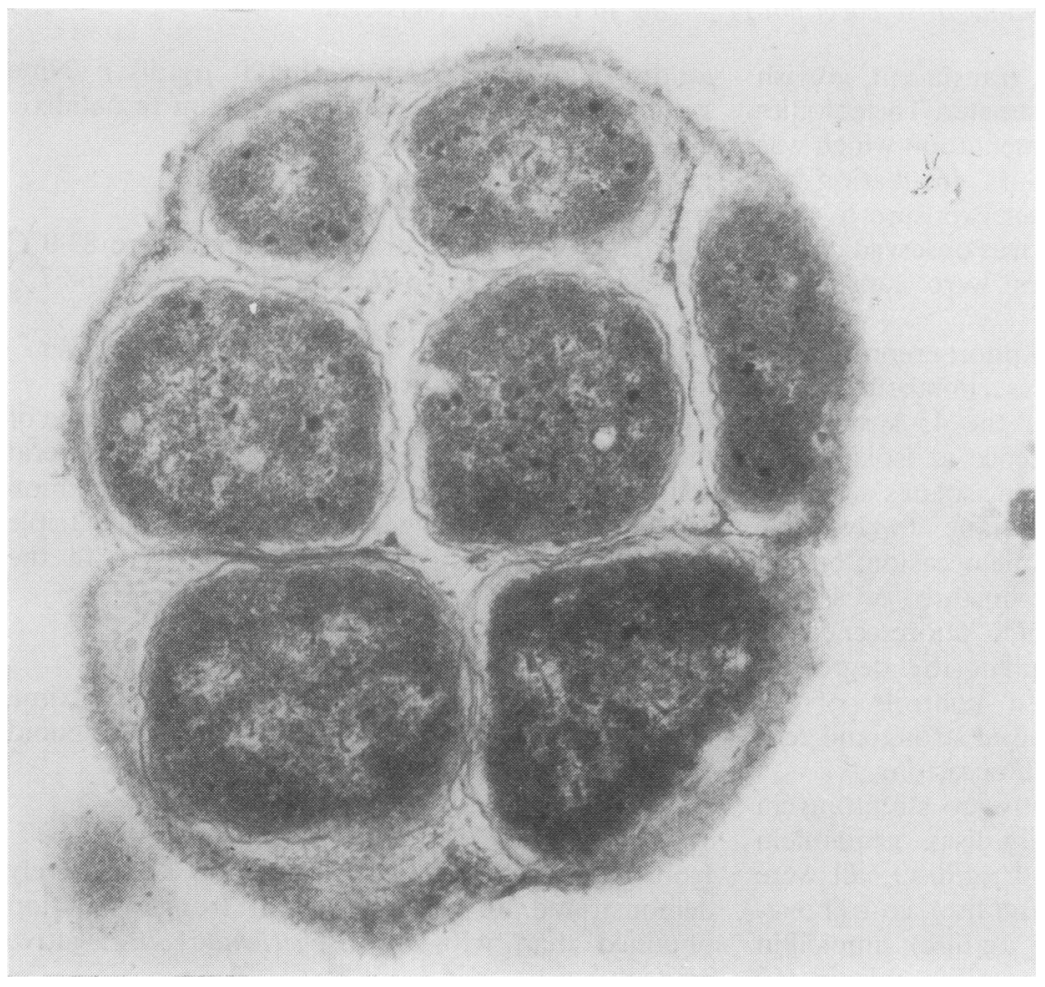

Fig 2 Groups of cells

apparently enclosed in a

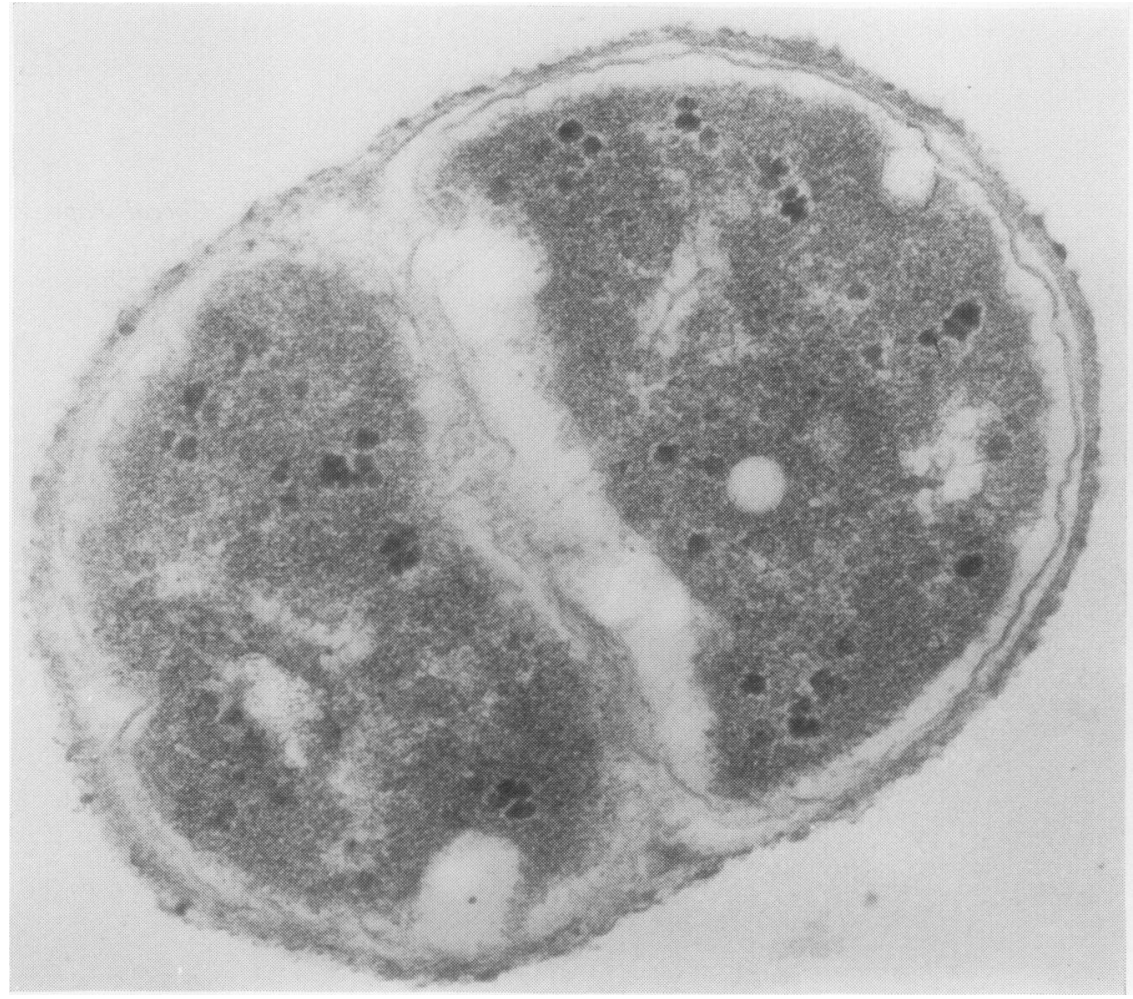

Fig 3 Ultrathin section showing detail of the cell wall, confirming the Gramnegative nature of this organism $(\times 20000)$. 


\section{Discussion}

The possibility cannot be excluded that the isolation of these organisms represents a cross infection episode. Attempts to recover this organism from materials used in the examination of the patients and the examination room environment were repeatedly unsuccessful. The recovery of strains from 10 patients on their first attendance and the observation of extracellular Gram-negative cocci in the direct smear of one of these weigh against this hypothesis.

We are unable definitely to assign these strains to a genus or species. Initially we considered that these strains might be classified in the genus Micrococcus. However, we rejected this possibility on the basis of what we consider to be the Gram-negative nature of our strains.

These were always Gram-negative with no evidence of retention of crystal violet even in the early stages of growth. Although some strains of micrococci may appear Gram-variable after prolonged incubation, we have never observed complete removal of crystal violet from all the cells.

Although the evidence from the electron microscope studies is not unequivocal, the fine structure appears more characteristic of a Gram-negative than a Gram-positive cell wall. Further evidence for the Gram-negative nature of our strains was obtained by comparing representative strains with some collection strains of Micrococcus roseus, including one highly mucoid strain. The findings can be summarized as follows:

The strains of $M$. roseus showed slight or no lysis with $0.5 \%$ sodium dodecyl sulphate, whereas our strains were rapidly and completely lysed. Growth of the $M$. roseus strains was inhibited by lysozyme, whereas our strains were resistant to $1 \mathrm{mg}$ of lysozyme. Strains of $M$. roseus showed little lysis after prolonged sonication, whereas our strains were completely lysed after only 30 seconds' sonication.

A relationship to the genera Acinetobacter or Neisseria is excluded by the DNA base composition of these isolates $(69 \%$ GC compared with $39-47 \%$ GC for Acinetobacter and 47-52\% GC for Neisseria). Our strains appear similar to those described by Courtois et al (1954), which they named Neisseria capsulata. However, the description of this species is not sufficiently detailed to allow conclusive comparison, and as far as we are aware the systematic position of this species has not subsequently been determined.

The arrangement of cells in what appear to be common capsules (fig 2) suggested Siderocapsa as a possible genus. However, the description of this genus in the 8th edition of Bergey's manual
(Buchanan and Gibbons, 1974) is incomplete, and we were unable to obtain any authentic strains of this genus for comparison. Our failure to demonstrate iron inclusion granules weighs against assignment to this genus.

The biochemical test results, DNA base compositions, and antibiotic sensitivity patterns of these strains suggest either Pseudomonas or Achromobacter as suitable genera for their inclusion. Our strains differ from the generic definition of Pseudomonas in being coccoid and non motile. Hendrie et al (1974) have recently proposed the rejection of the generic name Achromobacter. The genus Alcaligenes may be a suitable genus for some species previously classified as Achromobacter. However, many of the species in both these genera are poorly defined. Hendrie $e t$ al (1974) further considered that absence of motility should exclude strains from these genera. We therefore conclude that the systematic position of these strains should be left open until other workers have had the opportunity to examine our strains.

There is no evidence to suggest that this organism was playing a pathogenic role in any of the cases described here, and the significance of isolation of this organism from the urogenital tract lies in the superficial resemblance to the gonococcus, constituting a possible source of error in the diagnosis of this disease. Tests useful for the differentiation of this organism from $N$. gonorrhoeae are shown in table III. For practical purposes, profuse growths on nutrient agar and at $22^{\circ} \mathrm{C}$ form useful differential diagnostic tests.

\begin{tabular}{lll}
\hline & $\begin{array}{c}\text { Described } \\
\text { Strains }\end{array}$ & N. gonorrhoeac \\
\hline Growth on nutrient agar & + & - \\
Growth at $22^{\circ} \mathrm{C}$ & + & - \\
Growth on MacConkey agar & + & - \\
Urease production & + & - \\
Acid produced from glucose & - & + \\
Pink pigment & + & - \\
Accumulation of poly-B-hydroxy- & + & - \\
\hline
\end{tabular}

Table III Tests differentiating between the described strains and $\mathrm{N}$. gonorrhoeae

Three of these strains have been deposited in the National Collection of Type Cultures and allotted the following catalogue numbers-NCTC 10991, NCTC 10992, and NCTC 10993.

We should like to thank Dr J. L. Fluker for access to the clinical reports. DJP is in receipt of a grant from the Clinical Research Committee of the Charing Cross Hospital. 


\section{References}

Beck, A., Fluker, J. L., and Platt, D. J. (1974). Neisseria meningitidis in urogenital infection. Brit.J. vener. Dis., 50, 367-369.

Buchanan, R. E. and Gibbons, N. E., Eds. (1974). Bergey's Manual of Determinative Bacteriology, 8th edition. Williams and Wilkins, Baltimore.

Courtois, G., Thys, A., and Verselder, R. (1954). Une nouvelle Neisseria, agent causal de méningite. Ann. Soc. belge Méd. trop., 34, 13-20.

Cowan, S. T. and Steel, K. J. (1965). Manual for the Identification of Medical Bacteria. University Press, Cambridge.

Culling, C. F. A. (1974). Handbook of Histopathological and Histochemical Techniques, 3rd edition. Butterworth, London.

Hendrie, M. S., Holding, A. J., and Shewan, J. M. (1974). Emended descriptions of the genus Alcaligenes and of Alcaligenes faecalis and proposal that the generic name Achromobacter be rejected: status of the named species of Alcaligenes and Achromobacter: request for an opinion. Int. J. system. Bact., 24, 534-550.

Jephcott, A. E. and Morton, R. S. (1972). Isolation of Neisseria lactamicus from a genital site. Lancet, 2, 739-740.

Marmur, J. (1961). A procedure for the isolation of deoxyribonucleic acid from micro-organisms. J. molec. Biol., 3, 208-218.
Marmur, J. and Doty, P. (1962). Determination of the base composition of deoxyribonucleic acid from its therma denaturation temperature. J. molec. Biol., 5, 109-118.

Owen, R. J., Hill, L. R., and Lapage, S. P. (1969). Determination of DNA base compositions from melting profilese in dilute buffers. Biopolymers, 7, 503-516.

Owen, R. J. and Snell, J. J. S. (1973). Comparison of group IIf with Flavobacterium and Moraxella. Antonie Leeuwenhoek, 39, 473-480.

Pfennig, N. (1969). Rhodopseudomonas acidophila, sp.n. a new species of the budding purple nonsulfur bacteria. J. Bact., 99, 597-602.

Riddell, R. H. and Buck, A. C. (1970). Trimethoprim as an additional selective agent in media for the isolation of $\vec{\omega}$ N. gonorrhoeae. J. clin. Path., 23, 481-483.

Snell, J. J. S. and Davey, P. (1971). A comparison of methods for the detection of phenylalanine deamination by Morax ella species. J. gen. Microbiol., 66, 371-373.

Snell, J. J. S., Hill, L. R., and Lapage, S. P. (1972). Identifica-' tion and characterisation of Moraxella phenylpyruvica. J G clin. Path., 25, 959-965.

Volk, J. and Kraus, S. J. (1973). Asymptomatic meningo-o coccal meningitis. Brit. J. vener. Dis., 49, 511-513.

Wilkinson, A. E. (1952). Occurrence of Neisseria other than $\vec{c}$ the gonococcus in the genital tract. Brit. J. vener. Dis., 28, 24-27. 